\title{
Functional examination of IncRNAs in allotetraploid Gossypium hirsutum
}

\author{
Luyao Wang ${ }^{1,2,3}$, Jin $\mathrm{Han}^{3}$, Kening Lu², Menglin $\mathrm{Li}^{2}$, Mengtao Gao ${ }^{2}$, Zeyi $\mathrm{Cao}^{3}$, Ting Zhao ${ }^{3}$, Xue Chen², \\ Xiaoyuan $\mathrm{TaO}^{3}$, Quanjia Chen ${ }^{1 *}$ and Xueying Guan ${ }^{3,4^{*}}$ (1)
}

\begin{abstract}
Background: An evolutionary model using diploid and allotetraploid cotton species identified $80 \%$ of non-coding transcripts in allotetraploid cotton as being uniquely activated in comparison with its diploid ancestors. The function of the IncRNAs activated in allotetraploid cotton remain largely unknown.

Results: We employed transcriptome analysis to examine the relationship between the IncRNAs and mRNAs of protein coding genes (PCGs) in cotton leaf tissue under abiotic stresses. LncRNA expression was preferentially associated with that of the flanking PCGs. Selected highly-expressed IncRNA candidates $(n=111)$ were subjected to a functional screening pilot test in which virus-induced gene silencing was integrated with abiotic stress treatment. From this low-throughput screen, we obtained candidate IncRNAs relating to plant height and tolerance to drought and other abiotic stresses.

Conclusions: Low-throughput screen is an effective method to find functional IncRNA for further study. LncRNAs were more active in abiotic stresses than PCG expression, especially temperature stress. LncRNA XLOC107738 may take a cis-regulatory role in response to environmental stimuli. The degree to which IncRNAs are constitutively expressed may impact expression patterns and functions on the individual gene level rather than in genome-wide aggregate.
\end{abstract}

Keywords: IncRNA function, Conservation, Abiotic stress

\section{Background}

More than $90 \%$ of all transcripts in eukaryotic genomes cannot be translated into proteins. A large proportion of these transcripts are long non-coding RNAs (lncRNAs) [1]. Despite not being protein-coding, these IncRNAs are also under pressure for natural and human selection during evolution. A comparative analysis of the human and mouse genomes determined that lncRNAs are under positive selection rather than neutral mutation [2]. Some

\footnotetext{
*Correspondence: chajia@126.com; xueyingguan@zju.edu.cn

${ }^{1}$ Engineering Research Centre of Cotton, Ministry of Education / College of Agriculture, Xinjiang Agricultural University, 311 Nongda East Road, 830052 Urumqi, China

${ }^{3}$ College of Agriculture and Biotechnology, Zhejiang University, 210058 Hangzhou, Zhejiang, China

Full list of author information is available at the end of the article
}

IncRNAs are also known to be affected by positive selection in domesticated species, such as BRAFP in mammals [3]; altered expression of lncRNAs during domestication has likewise been identified in rice [4]. Therefore, lncRNAs actively take part in the evolution of species just as coding genes do. In addition, difference species exhibit distinctly different lncRNA profiles ; for example, the mouse and rat genomes share only 2,572 lncRNAs, comprising 12.7 and $11.1 \%$ of their total respective lncRNA profiles [5], and in citrus, no more than $10 \%$ of intergenic IncRNAs in Atalantia could be aligned to other citrus species [6]. However, a few functional lncRNAs are reported to be conserved across species; one such is Xist in mice and humans [7].

One mechanism by which noncoding RNAs can be functional is presented by the competitive endogenous

(c) The Author(s). 2021 Open Access This article is licensed under a Creative Commons Attribution 4.0 International License, which permits use, sharing, adaptation, distribution and reproduction in any medium or format, as long as you give appropriate credit to the original author(s) and the source, provide a link to the Creative Commons licence, and indicate if changes were made. The images or other third party material in this article are included in the article's Creative Commons licence, unless indicated otherwise in a credit line to the material. If material is not included in the article's Creative Commons licence and your intended use is not permitted by statutory regulation or exceeds the permitted use, you will need to obtain permission directly from the copyright holder. To view a copy of this licence, visit http://creativecommons.org/licenses/by/4.0/ The Creative Commons Public Domain Dedication waiver (http://creativecommons.org/publicdomain/zero/1.0/) applies to the data made available in this article, unless otherwise stated in a credit line to the data. 
RNA (ceRNA) hypothesis [3], which proposes different transcripts compete for binding of shared miRNAs. This hypothesis fits pseudogenes such as BRAFP1 that retain the miRNA targeting sequences of their parental coding genes and exhibit evolutionary conservation across species [8]. In contrast, the majority of lncRNA transcripts are generated from transposon elements and intergenic regions $[1,9]$.

The roles of IncRNAs in plants are of considerable interest, having emerged as new epigenetic regulators of coding gene expression in biological activities and as specifically affecting plant responses to abiotic stress [10-13]. In particular, lncRNAs are involved in transcriptional gene silencing, gene expression regulation, chromatin structural remodeling, and other epigenetic mechanisms $[14,15]$. Two common modes of regulation by lncRNAs involve non-local actions in trans and local actions in cis, which regulate the expression of adjacent genes [16-18]. For example, COLDAIR recruits PRC2 (Polycomb Repressive Complex 2) to regulate FLOWERING LOCUS C $(F L C)$ in trans [19], asDOG1 inhibits the transcription of DOG1 on the opposite chain acts in cis [20]. Although a number of lncRNAs have been identified, only a few are functionally well characterized. COOLAIR is a IncRNA with a conserved secondary structure, which has been proposed evolutionarily conserved across species and cis-regulate the $F L C$ [21, 22], MuLnc1 in mulberry [23], the involvement of cotton lncRNA973 in response to salt stress [24], IncRNA1459 altering tomato fruit ripening [25], and T5120 as a regulator of nitrate response and assimilation in Arabidopsis [26]. Though lncRNAs have been identified at the genome level in many plants or conditions [27-30], it remains difficult to characterize functional candidates.

The allotetraploid evolutionary model is an appropriate system to investigate IncRNA function. Within the diploid parent species and the allotetraploid species, non-coding regions can be compared in terms of sequence similarity and syntenic relationships. Furthermore, global genomic comparisons have revealed that lncRNAs burst in the process of polyploidization [31]. An analytical model system applying a comparative genomic method to allotetraploid cotton lncRNAs has been developed [31, 32]. The diploid ancestors of the cotton $A$ and D subgenomes underwent interspecific hybridization and polyploidy to form allotetraploid cotton one to two million years ago [33]. As research regarding the evolutionary genomics, population genetics, and epigenetics of allotetraploid cotton has developed rapidly [34-38], this provides a useful model system in which to further examine the rapid evolution of lncRNAs.

Thus, the functional relationship of lncRNA and protein-coding genes (PCGs) were further analyzed with the applied abiotic stresses in cotton leaves. We continued to use the IncRNA evolution system in cotton to investigate the functional lncRNAs in G. hirsutum.

\section{Results}

The source of IncRNAs activated in Gossypium hirsutum

The function of a lncRNA may be related to its sequence conservation, location on the chromosome, and transcriptional activity [39]. In our previous study, we respectively identified 4,107,2,381, and 8,514 lncRNAs in the G. arboreum (Ga), G. raimondii (Gr), and G. hirsutum (Gh) genomes. We then classified conserved lncRNAs (C-lncRNAs) and non-conserved lncRNAs (NC-lncRNAs) in Gh based on (1) the sequence similarity (blastn -evalue $10^{\wedge-10}$-max_target_seqs 1 ), (2) collinearity on the chromosome (MCscanX -b 2, -s 5) of the lncRNA for downstream functional analysis. A total of 693 lncRNAs in Gh were retained from $\mathrm{Ga}$ or $\mathrm{Gr}$, and 7821 were activated in Gh (Fig. 1, Table S1 and S2). That C-lncRNAs comprised only about $10 \%$ of all identified lncRNAs is in agreement with the common observation that most lncRNAs are unique to each species $[32,40]$.

\section{Expression pattern analysis of IncRNAs under abiotic stresses}

Plant IncRNAs are reported to be actively involved in the molecular regulation of responses to environmental stimuli and stresses. Abiotic stress is a serious threat that can lead to significant losses of all field crops, including cotton [41]. To validate the association of IncRNA expression with stress in cotton, we performed four abiotic stress assays on cotton seedlings: drought, sodium chloride $(\mathrm{NaCl})$, heat, and cold treatment. The leaves of the treated seedlings were harvested for RNA-seq profiling (Fig. 1), which revealed that both lncRNAs and proteincoding genes (PCGs) tended to be expressed specifically under stress; however, In both lncRNAs (total:8,514) and PCGs(total:70,478), the percentage of differentially expressed lncRNAs (DE-lncRNAs)was lower than the percentage of differentially expressed protein coding genes (DE-PCGs) (Fig. 2A-B; Table S3). The DElncRNAs showed a significant divergence of expression pattern relative to PCGs when plants were subjected to abiotic stresses, especially heat and cold. In particular, high temperatures tended to up-regulate lncRNAs, whereas low temperatures down-regulated them (Fig. 2C-E). Meanwhile, C-lncRNAs and NC-lncRNAs showed no significant difference in terms of their stressresponsive expression patterns (Fig. 2C; Table S3). Finally, biological replicates of the RNA-seq results showed high consistency (Fig S1). These findings suggest that abiotic stresses, and especially temperature stress, proactively stimulate lncRNA expression more than 


\section{G. arboreum G. raimondii}

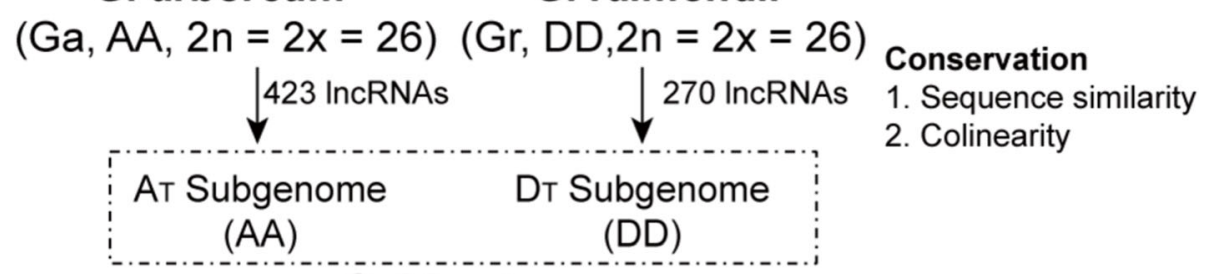

\section{G. hirsutum}

(Gh, AADD, $2 n=4 x=52$ )

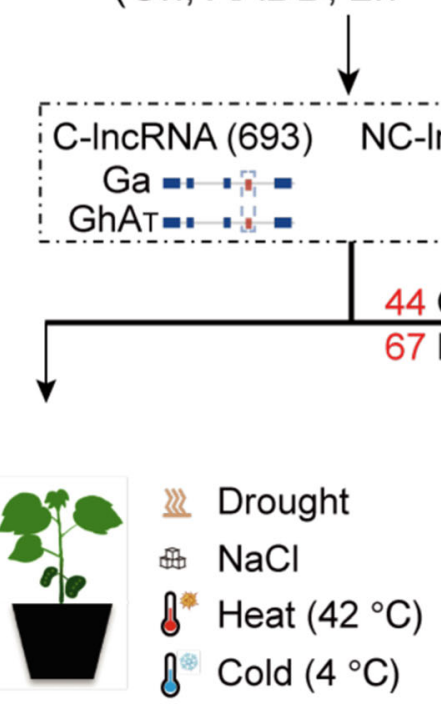

RNA-sequencing

44 C-IncRNAs

$67 \mathrm{NC}-$ IncRNAs

Fig. 1 Workflow of functional IncRNA screening in upland cotton (Gossypium hirsutum)

PCG expression. The correlation between lncRNAs and PCGs in response to stimuli has yet to be studied.

\section{Co-expression of IncRNAs with adjacent PCGs}

The lncRNA-mediated regulation of gene expression occurs in either cis or trans [42]. To investigate potential patterns in the mode by which lncRNAs regulate PCGs, we examined the association of their expression profiles in the context of abiotic stress. Here we defined a 1:1 orthologous adjacent PCG that co-expressed with a lncRNA within $50 \mathrm{~kb}$ as being subject to a cis effect of the lncRNA, consistent with the latest literature [5, 32]. The correlation of expression between lncRNAs and their adjacent PCGs (lncRNA/Control) was significantly high (Fig. 2F; $p=.0006358$, Table S4) compared with that between neighboring PCGs (PCG/Control). And no significant difference was found between C-lncRNA/ Control and NC-lncRNA/Control (Fig. 2G; $p=.3352$, Table S5). The above results are consistent with documented lncRNA dynamics in mice [5], and indicate that most lncRNAs tend to play a role in cis gene regulation. By combining the expression pattern in stress and expression with adjacent PCGs, we also found that lncRNA conservation level is independent of its function and regulation pattern.

\section{Functional examination of IncRNAs in allotetraploid cotton}

Several functional studies have reported that lncRNAs can play roles in growth, development, and abiotic stresses in rice, cotton, and other plants [24, 28, 43-47]. Therefore, in this study, we carried out a functional evaluation of lncRNAs in upland cotton (G. hirsutum, acc. Texas Marker-1 [TM-1]) by applying virus-induced gene silencing (VIGS) treatment and assessing plant height and tolerance of four abiotic stresses (drought, $\mathrm{NaCl}$, heat $\left[42{ }^{\circ} \mathrm{C}\right]$, and cold $\left[4{ }^{\circ} \mathrm{C}\right]$ ) (Figs. 1 and $3 \mathrm{~A}$ ). We also evaluated transcriptional activity in leaves in terms of FPKM. Candidate lncRNAs were selected on account of having top-ranking transcriptional activity. Ultimately, 


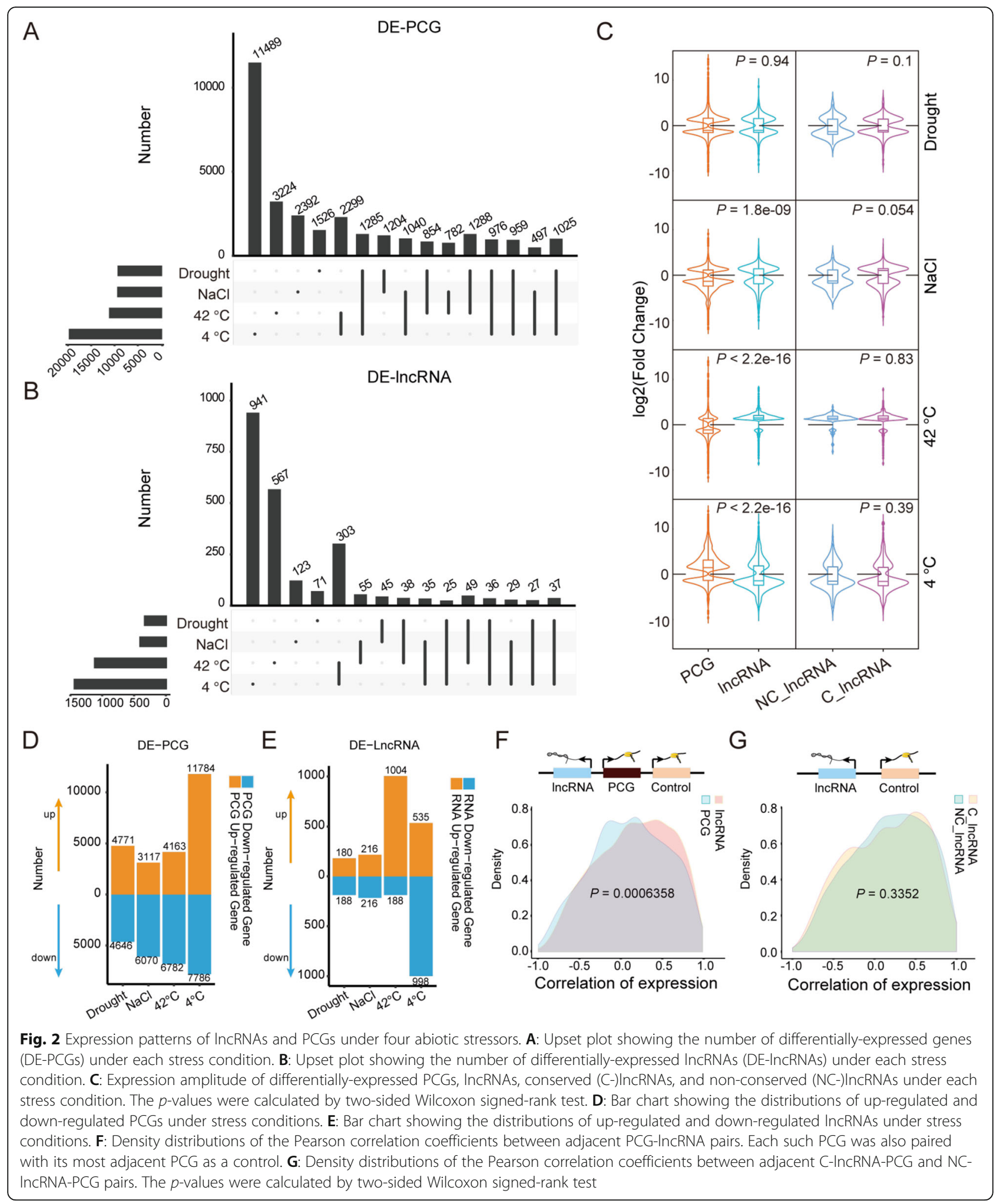

$67 \mathrm{NC}$-lncRNAs and $44 \mathrm{C}$-lncRNAs were cloned and subjected to VIGS. And 56 (out of 111) lncRNAs affected the phenotype, suggesting they are protentionally involved with correlated biological functions (Figs. 1 and
3B). In terms of lncRNA function, 20 (out of 111 observed) affected plant height, and 34 (out of 90 observed) affected plant death rate in drought abiotic stress. Both positive and negative correlation between the lncRNA 


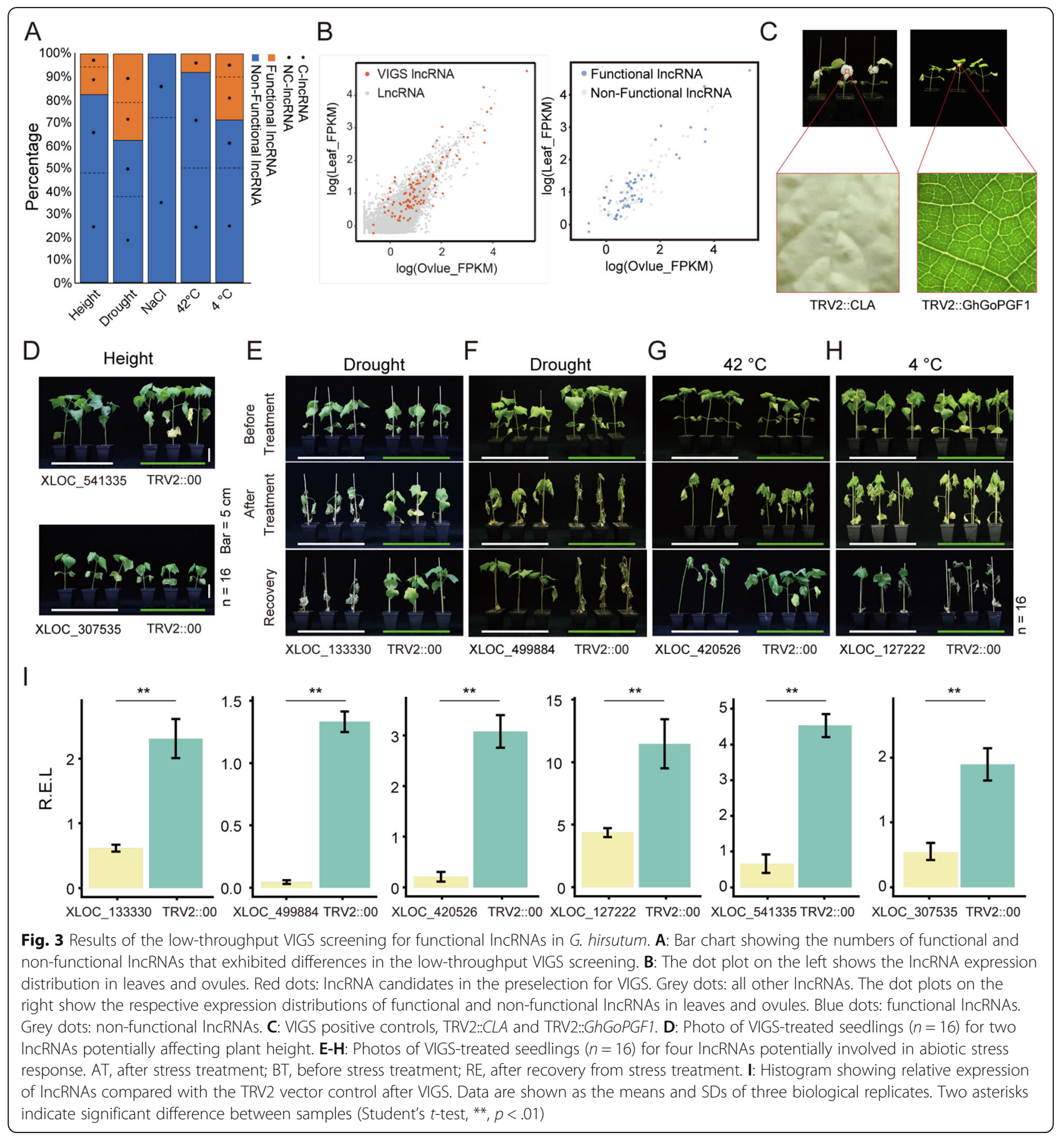

and the phenotype were observed as shown in Table S6. Zero lncRNAs (out of 36 observed) were found to be related to $\mathrm{NaCl}$ tolerance. One (out of 12 observed) was related to heat tolerance, and five (out of 13 observed) showed differential response to cold stress (Fig. 3A, Table S6). Overall, most of the potential functional lncRNAs that were screened were associated with abiotic stress.

The selection of phenotypic lines after VIGS is shown in Fig. $3 \mathrm{C}-\mathrm{H}$, with transcription suppression of the corresponding lncRNA shown in Fig. 3I. The primary results identified XLOC_133330 and XLOC_499884 as related to drought stress, XLOC_420526 and XLOC_127222 as associated with temperature changes, and XLOC_541335 and XLOC_707056 as involved in plant development regulation. Detailed information and phenotypic observations of lncRNAs after VIGS silencing are given in Table S6. These findings indicate that cotton lncRNAs are actively associated with growth and stress tolerance regulation. 


\section{Functional validation of IncRNAs identified in the low- throughput screen}

To validate the accuracy of the low-throughput functional examination, representative functional lncRNAs were further assessed. Specifically, we examined two candidates from the functional pilot tests to doublecheck their phenotypes and examine their potential regulation patterns (cis/trans).

The first, XLOC_227558, was a C-lncRNA in G. hirsutum on chromosome A08, with a syntenic IncRNA, XLOC_393369, in G. arboreum on chromosome 3 (Fig. 4A). After silencing XLOC_227558, TM-1 seedlings exhibited a drought-sensitive phenotype (Fig. $4 \mathrm{~B}$ and C, Table S6). ABA plays an important role in plant drought stress response, and some specific genes in the ABA pathway have been singled out as involved, such as ABSCISIC ACID RESPONSIVE ELEMENT-BINDING FACTOR 1 (ABF1), PYRABACTIN RESISTANCE 1-LIKE 9 (PYL9), and DEHYDRATION-RESPONSIVE PROTEIN $R D 22$ (RD22) [48]. To observe whether silencing of $X L O C \_227558$ affected the ABA pathway, we carried out a quantitative analysis of $A B F 1, P Y L 9$, and $R D 22$. Expression of $A B F 1$ was decreased in XLOC_227558-silenced plants (Fig. 4D-G). Meanwhile, XLOC_227558 expression did not correlate with that of its adjacent PCG (Gh_A08G1105) (Fig. 4I), and the co-expression network of Gh_A08G1105 displayed no direct evidence of correlation with drought stress (Fig. 4 F; Table S7).

The second candidate selected for validation, the NClncRNA XLOC_107738, also yielded a drought-sensitive phenotype after silencing (Fig. $5 \mathrm{~A}$ to $\mathrm{C}$, Table S6). In $X L O C_{-}$107738-silenced plants, expression of $A B F 1$ was likewise decreased while that of $R D 22 A$ and $R D 22 D$ was increased (Fig. 5D-G). Expression of XLOC_107738 was correlated with that of its adjacent gene Gh_A05G0714 (RPS11). Two genes co-expressed with Gh_A05G0714 related to photosystem II (Fig. $5 \mathrm{H}-$-J; Table S8), namely Gh_D07G1455, which encodes the photosystem II reaction center protein C (psbC), and Gh_A02G0992, which encodes the photosystem II reaction center protein $B$ (psbB). As chloroplasts and photosynthesis are actively involved with abiotic and biotic stress in plants [49], we speculated that XLOC_107738 might act in cis to adjust the drought tolerance of cotton. These findings confirmed that both conserved and non-conserved lncRNAs can play a role in cotton stress regulation.

\section{Discussion}

\section{The rapid evolution of IncRNAs to obtain new functions}

Rapid evolution of IncRNAs is commonly observed in both plant and animal kingdoms in the form of interspecies polymorphisms and epigenomic modifications [39, 50]. For example, diverged Arabidopsis ecotypes show polymorphisms in the promoter region of the flowering gene FRIGIDA INTERACTING PROTEIN 1 (FIP1), and DNA demethylation associated with lncRNA transcripts can be inherited [51]. Furthermore, whole-genome duplication and domestication can specifically induce lncRNA origin to drive their fast evolution [31]. In comparisons between wild and cultivated cotton varieties, lncRNA transcripts were relatively stable and fixed after polyploidization in wild populations, races, and cultivars alike [31]. These data indicate that environmental stimuli introduced transcriptional variation via inheritable epigenetic modifications, from which beneficial phenotypes were obtained [51-56]. Our study on functional lncRNAs in allotetraploid cotton confirms that the rapid evolution of lncRNAs introduces new, functional noncoding genes.

Among lncRNAs, no statistical difference in the response to stimuli was observed for C-lncRNAs compared with either all IncRNAs or NC-IncRNAs. Furthermore, our primary functional screening indicated that in the cotton lineage, both C-lncRNAs and NClncRNAs have biological roles. In our study, the definition of conserved lncRNA is based on sequence similarity; however, conserved lncRNAs reported to be functional show low sequence similarity. Some structural elements, such as an RNA-loop, could be sufficient for lncRNA function; thus, our definition of conservation may underestimate the impacts from features such as short motifs or secondary structures. However, the trend observed in our study also supports that NC-lncRNAs have the chance to gain a new regulatory role and, for cotton, were selected in the cultivated population. These results are in agreement with the notion that epigenetic modifications associated with beneficial traits are under positive selection. We therefore speculate that inheritable and functional epigenetic modifications can play a role in the rise of domesticated traits. Polymorphisms of epigenetic modifications in a natural population may thus be an unknown reservoir of genetic markers for the development of new germplasms.

\section{Using the RNA silencing technology of VIGS to validate the LncRNA function}

LncRNAs are abundantly present and transcribed in the genome [57]; however their gene structure and transcriptional activity are relatively unstable compared with PCGs $[58,59]$. Utilization of cell lines may aid in achieving high-throughput screening with strong transcriptional signal, but lncRNA function is often cell-type specific, thus the cultured cells may not reflect the real functions of the lncRNAs [60]. Multiple published studies have carried out functional lncRNA screenings with various strategies, including reverse genetics, which uses CRISPRi technology [29, 60]; comparative genomics and transcriptome-based prediction across species, wild 
A

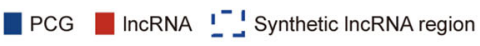

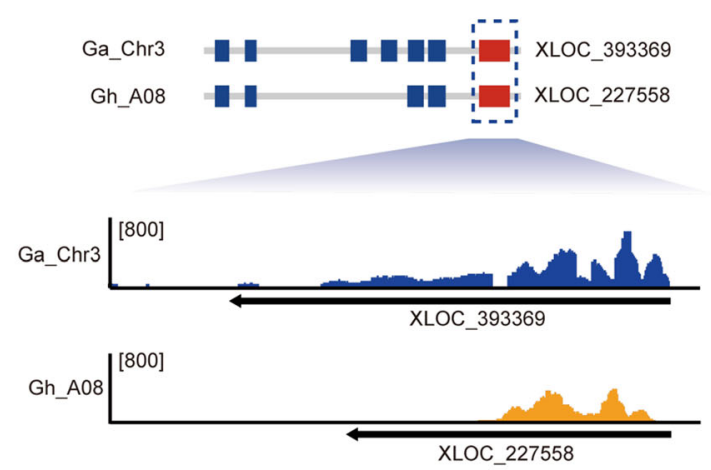

B

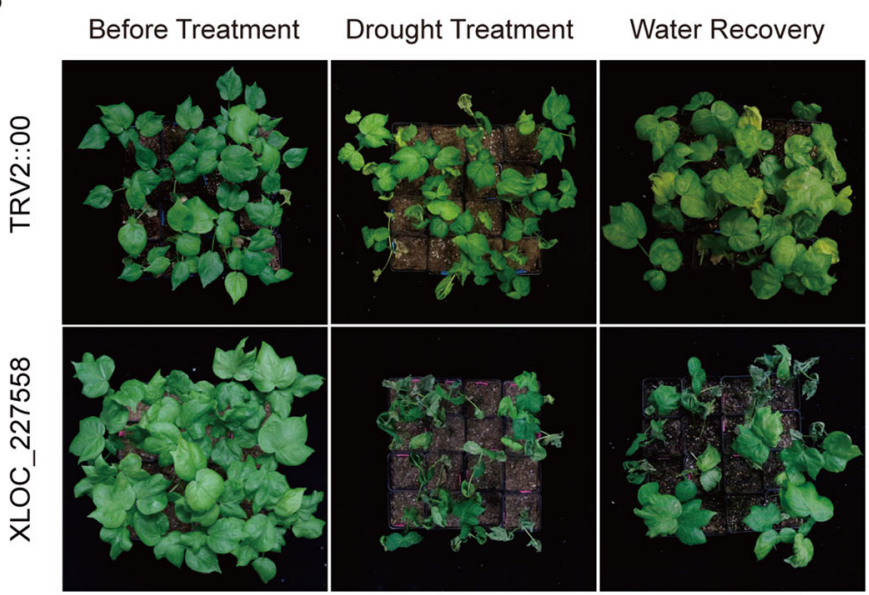

G
C

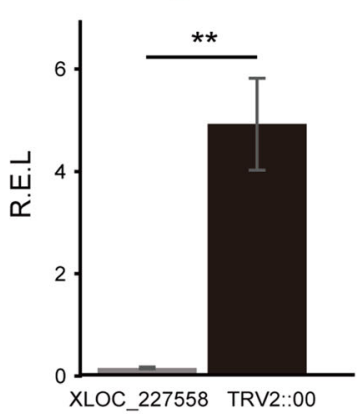

H

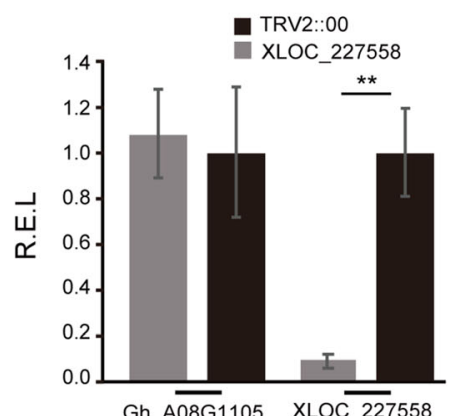

D

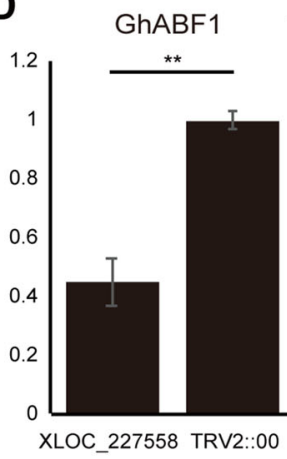

E

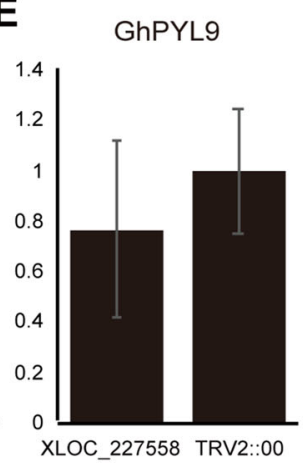

I
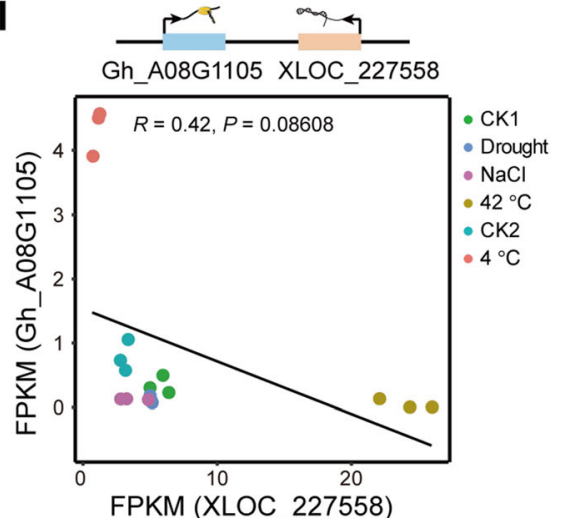

F
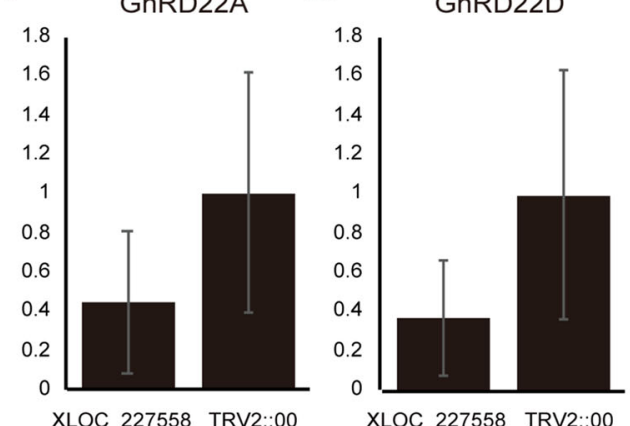

J

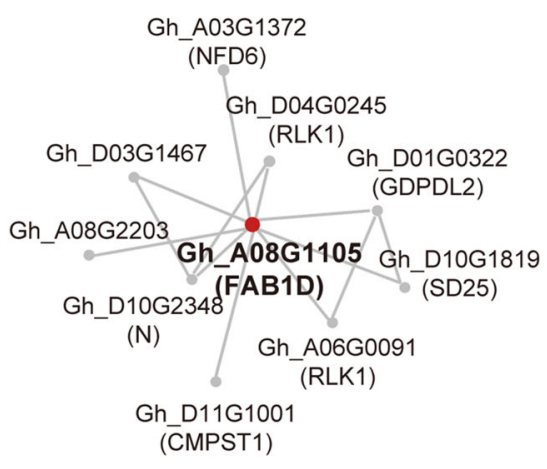

Fig. 4 A representative C-IncRNA that screened as affecting cotton seedling drought tolerance. A: Schematic showing the collinear position of XLOC_227558, between Gossypium arboreum (Ga) chr3 and Gossypium hirsutum (Gh) A08. This gene is syntenic with XLOC_227558. The lower graph shows a stack view of the locus with leaf RNA-seq reads from Ga and Gh. Blue box, PCGs; red box, IncRNAs; dashed box, syntenic IncRNA region. B: Photos showing cotton seedlings $(n=16)$ treated with TRV2::XLOC_227558 and TRV2::00 before drought treatment, after drought treatment, and after water recovery. Bar $=5 \mathrm{~cm}$. C: Histogram showing the relative expression level of XLOC_227558 in TRV2::XLOC_227558 and TRV2::00 treated plants as quantified by qRT-PCR. Error bar: standard error of the mean. Asterisks indicate significant difference between samples (Student's t-test, ${ }^{*}, p<.05 ;{ }^{* *}, p<.01$ ). R.E.L., relative expression level. D-G: Histograms showing the respective relative expression levels of GhABF1, GhPYL9, GhRD22A, and GhRD22D in TRV2::XLOC_227558 and TRV2::00 treated plants as quantified by qRT-PCR. Error bar: standard error of the mean. Asterisks indicate significant difference between samples (Student's t-test, ${ }^{*}, p<.05 ;{ }^{*}, p<.01$ ). R.E.L., relative expression level. H: Histogram showing the relative expression of XLOC_227558 and its adjacent PCG Gh_A08G1105 as determined by qRT-PCR. Error bar: standard error of the mean. Asterisks indicate significant difference between samples (Student's t-test, $\left.{ }^{*}, p<.05 ;{ }^{*}, p<.01\right)$. I: Scatterplot showing the linear relationship between expression of XLOC_227558 and that of the adjacent PCG, Gh_A08G1105, under different abiotic stressors. J: Co-expression network of Gh_A08G1105 


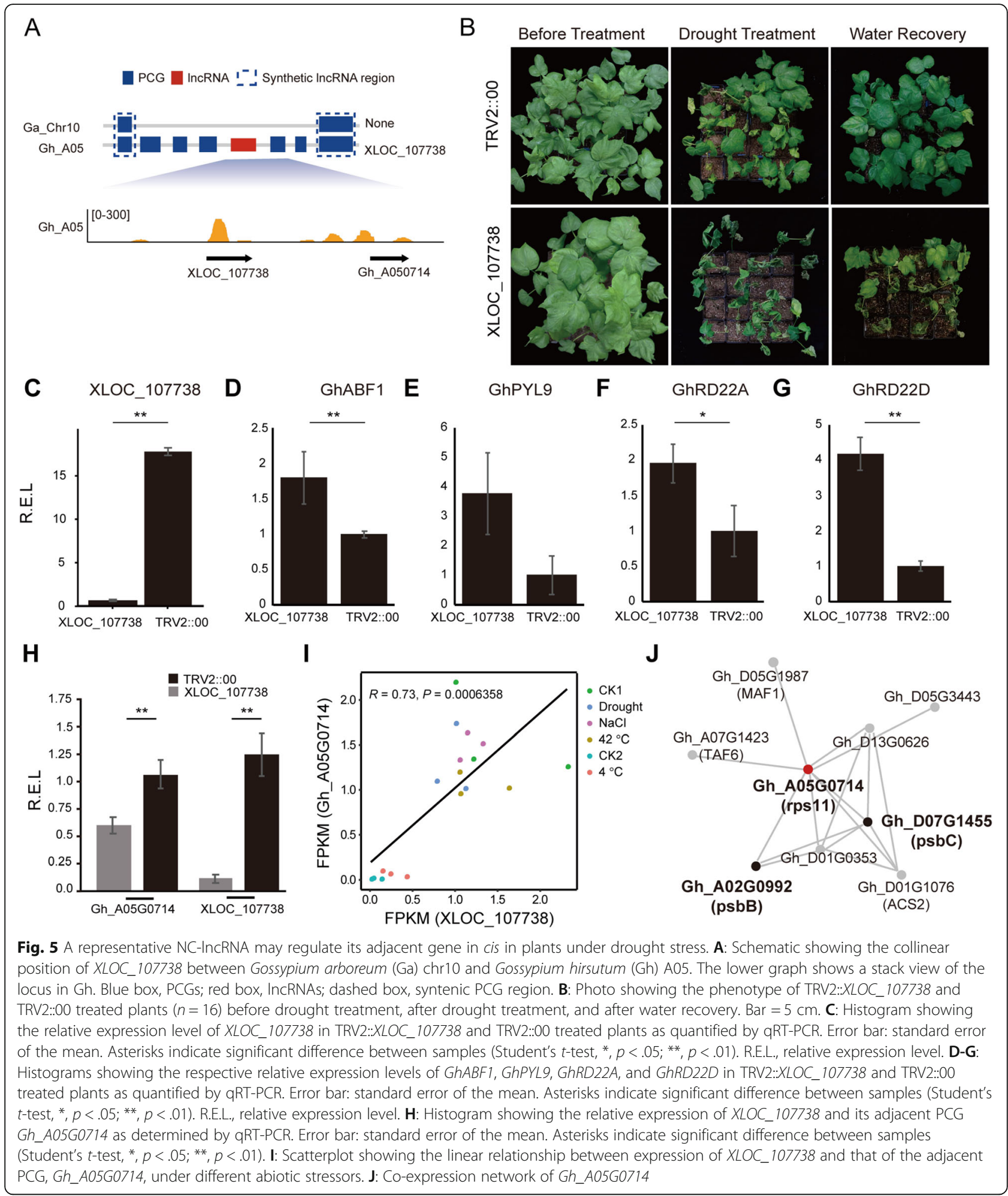

species, and cultivars [4, 39]; and mapping based on epigenetic recombination lines $[54,61]$. Highthroughput CRISPRi operations made great improvement on testing the lncRNA function. The typical CRISPRi operation is targeted for short DNA fragment editing of 1 to 10 base pairs, which may not significantly influence RNA transcription at the edited site [62]. Likewise, RNA silencing technology of VIGS used in this study should be an efficient gene operation of functionla lncRNA screening. 
In general, most lncRNAs are responsive to or play roles in responses to environmental stimuli. However, it is noteworthy that in both animal and plant populations, high-throughput screening has not identified a specific biological function for C-lncRNAs. The reported low conservation of IncRNAs across species and the screening-out of conserved lncRNAs among functional candidates in this study suggest that the potential functionality of each conserved non-coding gene needs to be considered as an individual case. That is, degree of lncRNA conservation shows little correlation to function at the genome-wide level. This observation favors our conclusion that IncRNA function is unique to species and to lineage over the course of evolution. The results of the present study might be skewed due to the small number of conserved lncRNAs, but that the functional lncRNA profile is unique to each organism is in agreement with most of the reported biological impacts of lncRNAs.

\section{Conclusions}

The impact of lncRNA conservation on expression patterns and functions may operate at the level of individual genes rather than genome-wide. The development of inheritable and functional lncRNAs over evolution can participate in the emergence of adaptive traits.

\section{Methods}

\section{Plant materials}

Plants of the upland cotton (G. hirsutum) genetic standard line Texas Marker-1 (TM-1) [63] were obtained from the Agricultural Research Service, U.S. Department of Agriculture, and the Texas Agricultural Experiment Station. Plants were cultivated in a growth chamber at 25 to $28{ }^{\circ} \mathrm{C}$ with a light/dark cycle of $16 / 8$ hours. All were planted in $6.5 \mathrm{~cm} * 6.5 \mathrm{~cm}$ plastic pots filled with a 1:1 (v/v) mixture of commercial humus:commercial vermiculite.

\section{Plasmids and constructs}

Unique 200- to 400-bp fragments of IncRNAs were amplified from TM-1 cDNA by polymerase chain reaction (PCR) using Ex Taq (Takara, Code No.: RR01AM). The primer list is given in Table S9. PCR products were cloned into EcoR I-BamH I-digested pTRV2 to produce a VIGS vector. Resulting constructs were introduced into Agrobacterium tumefaciens strain GV3101 by liquid nitrogen transformation.

\section{Virus-induced gene silencing}

TM-1 plants were cultivated in a growth chamber under conditions of $16 \mathrm{~h} / 8 \mathrm{~h}$ light/dark and $21{ }^{\circ} \mathrm{C} \pm 1{ }^{\circ} \mathrm{C}$. Plants used for gene silencing were approximately eight days old when their cotyledons expanded. For each experiment, A. tumefaciens harboring pTRV1, pTRV2 (TRV2:00), TRV2::CLA (Cloroplastos alterados 1) [64], TRV2::GhGoPGF1 [65], and pTRV2 containing host target genes were grown on Luria broth (LB) agar plates supplemented with $50 \mu \mathrm{g} / \mathrm{mL}$ of kanamycin and $25 \mu \mathrm{g} /$ $\mathrm{mL}$ of rifampicin. The plates were incubated at $28^{\circ} \mathrm{C}$ for two days. Plasmids TRV2::CLA and TRV2::GhGoPGF1 were utilized as positive controls, and the empty vector TRV2::00 was the negative control. Silencing of CLA causes the plants to become photobleached, and this was used as a silencing efficiency control. For each strain, 3$\mathrm{mL}$ primary liquid culture of LB was inoculated with the above-mentioned antibiotics and was incubated with shaking at $200 \mathrm{rpm}$ at $28{ }^{\circ} \mathrm{C}$ for 14 to $16 \mathrm{~h}$. A 1:100 dilution of the primary culture was then inoculated into a secondary liquid induction media culture with $50 \mu \mathrm{g} / \mathrm{mL}$ of kanamycin and $25 \mu \mathrm{g} / \mathrm{mL}$ of rifampicin, which was incubated with shaking at $28^{\circ} \mathrm{C}$ for 14 to $16 \mathrm{~h}$ at $200 \mathrm{rpm}$ until the $\mathrm{OD}_{600}$ was 1.5 to 2.0. The cells were then harvested by centrifugation for ten minutes at $4000 \mathrm{x} g$ and were resuspended in a culture medium with $10 \mathrm{mM}$ magnesium chloride, $10 \mathrm{mM}$ MES, and $200 \mu \mathrm{M}$ acetylacetone. For each culture, a bacterial suspension with an $\mathrm{OD}_{600}$ of 2.0 was prepared and incubated in the dark at $28{ }^{\circ} \mathrm{C}$ for three to five hours. Cultures containing the pTRV1 vector and the pTRV2 vector with the gene of interest were mixed at a 1:1 ratio. The bacterial suspensions were infiltrated into the cotyledons of the seedlings, and the plants were kept at $21{ }^{\circ} \mathrm{C} \pm 1{ }^{\circ} \mathrm{C}$ in a growth chamber with a 16-hour day length and $50 \%$ relative humidity for at least three weeks before use in assays.

\section{Height observation and stress treatment of cotton plants with virus-induced gene silencing}

TM-1 plant height (from cotyledon to growth point) and leaf number were measured about 30 days after VIGS. For drought stress, plants were irrigated with sufficient water, then subject to water restriction until those infected with TRV2::IncRNA or TRV2::00 were dying. Soil water content (SWC) was determined according to the formula: $\operatorname{SWC}(\%)=(\mathrm{Ww}-\mathrm{Wd}) /(\mathrm{Wd}-\mathrm{Wt}) \times 100 \%$, where $\mathrm{Ww}$ is the wet mass of soil in tube, Wd the dry mass of soil in tube (after over-drying at $80{ }^{\circ} \mathrm{C}$ until a constant mass was obtained), and Wt is the mass of the empty tube [24]. Leaf samples were harvested right before water restriction and were immediately frozen in liquid nitrogen and stored at $-80{ }^{\circ} \mathrm{C}$. Plants were photographed before and after the water restriction and subsequent rewatering. For $\mathrm{NaCl}$ stress, plants were irrigated with $200 \mathrm{mM} \mathrm{NaCl}$ instead of water. For heat stress, the plants were placed in a $42{ }^{\circ} \mathrm{C}$ incubator until those treated with TRV2::IncRNA or TRV2::00 were dying. For cold stress, plants were placed in a $4{ }^{\circ} \mathrm{C}$ 
incubator until those treated with TRV2::IncRNA or TRV2::00 were dying. Survival rates were scored after plants were restored to normal growth conditions for seven days. Each group consisted of 16 replicates.

\section{cDNA synthesis and quantitative polymerase chain reaction}

Total RNA was isolated using an RNA extraction kit (RK-16, Zhong Ding, Nanjing, China), and first-strand cDNA synthesis was performed using HiScript ${ }^{\oplus}$ II (Vazyme). Gene-specific primers were used for the SYBR Green-based qPCR, which was performed on an ABI StepOnePlus system with $20 \mu \mathrm{L}$ of $100 \mathrm{ng}$ of $\mathrm{CDNA}, 4$ pM of each primer, and $10 \mu \mathrm{L}$ of AceQ qPCR SYBR Green Master Mix (Vazyme, Nanjing, China) according to the manufacturer's protocol. The thermal cycle conditions were as follows: $95{ }^{\circ} \mathrm{C}$ for three minutes, then 40 cycles of $95{ }^{\circ} \mathrm{C}$ for $15 \mathrm{~s}, 60{ }^{\circ} \mathrm{C}$ for $15 \mathrm{~s}$, and $72{ }^{\circ} \mathrm{C}$ for $30 \mathrm{~s}$. Relative expression levels were calculated using the $2-\Delta \Delta$ Ct method. Histone 3 (AF024716) was used as an internal control for normalization. The primer sequences are listed in Table S10.

\section{Classification of C-IncRNA and NC-IncRNA}

The lncRNA sequences and genome coordinate files of G. arboreum (Ga), G. raimondii $(\mathrm{Gr})$, and G. hirsutum (Gh) were previously generated by our laboratory and are deposited in Github repositories (https://github.com/ epi-cotton/LncRNA-in-polyploid-cotton). Conservation was determined based on synteny and sequence similarity. MCScanX [66] was used to analyze the multicollinearity between $\mathrm{Ga}$ and $\mathrm{GhA}_{\mathrm{T}}$ and $\mathrm{Gr}$ and $\mathrm{GhD}_{\mathrm{T}}$ (blastn -evalue $10^{\wedge^{-10}}$-max_target_seqs 1 ; MCscanX file -b 2, -s 5) [31]. Individual transcript expression levels were quantified in terms of the fragments per kilobase of exon per million fragments (FPKM) by StringTie [67].

\section{Expression profiling of stress-treated cotton plants by RNA-seq}

Cotton seedlings with four expanded leaves were used for stress treatments. Cold treatment was carried out at $4{ }^{\circ} \mathrm{C}$, heat at $42{ }^{\circ} \mathrm{C}$, salt with $200 \mathrm{mmol} \mathrm{NaCl}$, and drought in the form of water restriction. All plants were grown in chambers with a light/dark cycle of $16 / 8$ hours. Leaf tissues were harvested after 30 days of treatment and frozen with liquid nitrogen for RNA extraction and sequencing (Table S11). Read quality was assessed before and after trimming using FastQC [68]. Reads were aligned to the reference genome G. hirsutum V1.0 [36] using HISAT2 [69], and the resulting BAM files were sorted and indexed using SAMtools [70]. Expression (FPKM) was calculated by StringTie [67], and differential gene expression was determined using DESeq [71] with a false discovery rate threshold of 0.05 .

\section{Co-expression with adjacent coding genes}

Cotton lncRNAs (with filtered lncRNAs) were assigned to their nearest PCG using bedtools based on the distance between gene bodies. Each PCG assigned to a lncRNA was then matched to its immediate neighboring PCG, which was used as a control. We estimated the Pearson's expression correlation and performed a twosided Wilcoxon signed-rank test between the lncRNA/ control and PCG/control pairs using.The same analysis was also carried out for C-lncRNA/control and NClncRNA/control pairs.

\section{Co-expression network}

The co-expression network for lncRNAs was constructed as described previously. Positive and negative co-expression networks for PCGs were generated online (http://structuralbiology.cau.edu.cn/gossypium/) [72].

\section{General statistics and plots}

All statistical analyses were performed in R (https:// www.r-project.org/) using the packages data.table and stats. All plots were generated in $\mathrm{R}$ using the packages ggplot2 (https://cran.r-project.org/web/packages/ggplot2/ index.html), ggpubr (https://cran.r-project.org/web/ packages/ggpubr/index.html), pheatmap (https://cran.rproject.org/web/packages/pheatmap/index.html), and gmodels (https://cran.r-project.org/web/packages/ gmodels/index.html).

\section{Abbreviations}

IncRNA: Long non-coding RNAs (IncRNAs); C-IncRNA: Conserved IncRNA; NCIncRNA: Non-conserved IncRNA; PCG: Protein-coding gene; FPKM: Fragments Per Kilobase of exon model per Million mapped fragment; DE-

PCGs: Differentially expressed protein-coding genes; DE-

IncRNAs: Differentially expressed IncRNAs; kb: Kilobase; bp: Base pair; TM-

1: Texas Marker-1

\section{Supplementary Information}

The online version contains supplementary material available at https://doi. org/10.1186/s12864-021-07771-3.

Additional file 1: Figure S1. Examination of repeatability among RNA sequencing samples. A: Heatmaps correlating expression levels among samples based on the RNA-seq profiles of cotton seedlings treated with drought, $\mathrm{NaCl}$, and heat. B: Heatmaps correlating expression levels among samples based on the RNA-seq profiles of cotton seedlings treated with cold.

Additional file 2: Figure S2. Examination of PCG and IncRNA associations. A: Phenotypes of seedlings treated with positive control TRV2::CLA. B: Phenotypes of seedlings treated with TRV2::00 and positive control TRV2::GhGOPGF1. C: Soil water content before drought treatment for seedlings receiving TRV2::XLOC_227558and TRV2::00. D: Soil water content after drought treatment for seedlings receiving TRV2::XLOC_227558 and TRV2::00. E: Soil water content before drought treatment for seedlings receiving TRV2:: XLOC_107738 and TRV2::00. F: Soil water content after drought treatment for seedlings receiving TRV2:: XLOC_107738 and TRV2::00

Additional file 3: Table S1. List of C-IncRNAs in GhA and corresponding syntenic IncRNA in Ga. 
Additional file 4: Table S2. List of C-IncRNAs in GhD- and corresponding syntenic IncRNA in Gr.

Additional file 5: Table S3. Counts of differentially-expressed PCGs and IncRNAs under four stress treatments.

Additional file 6: Table S4. Expression of adjacent PCG-IncRNA pairs and adjacent PCG-PCG pairs.

Additional file 7: Table S5. Expression of adjacent C-IncRNA-PCG and NC-InCRNA-PCG pairs.

Additional file 8: Table S6. Expression, conservation level, and associated phenotype of IncRNAs subjected to VIGS.

Additional file 9: Table S7. Annotations of genes co-expressed with Gh_A08G1105.

Additional file 10: Table S8. Annotations of genes co-expressed with Gh_A05G0714.

Additional file 11: Table S9. The primers for IncRNA VIGS construct cloning.

Additional file 12: Table S10. $q P C R$ primers used in this study

Additional file 13: Table S11. Statistics of RNA-seq libraries in this study.

\section{Acknowledgements}

We would like to thank the Dabeinong Funds for Discipline Development and Talent Training at Zhejiang University, the Fundamental Research Funds for the Central Universities.

\section{Authors' contributions}

X.G. conceptualized the project. L.W., J.H., K.L., M.L., M.G., Z.C., and X.C. carried out the experiments. L.W. and T.Z. performed the bioinformatics analysis, L.W., X.T., Q.C., and X.G. prepared the manuscript. All the authors read and approved the final manuscript.

\section{Funding}

All reagents and computational infrastructure applied in this research are supported by grants from the National Key Research and Development Program (2016YFD0100605) to X. G., the National Natural Science Foundation of China (NSFC, 31971985, 31900395, 32000379, 31901430), the funding of "Leading Innovative and Entrepreneur Team Introduction Program of Zhejiang" (2019R01002). Funding bodies had no direct involvement in study design, sample collection, data analysis, data interpretation, or manuscript preparation.

\section{Availability of data and materials}

The IncRNA sequences and genome coordinate files are provided at https:// github.com/epi-cotton/LncRNA-in-polyploid-cotton. The Illumina RNA-seq data are available at the Sequence Read Archive under the accession number PRJNA631851.

\section{Declarations}

Ethics approval and consent to participate

Not applicable.

\section{Consent for publication}

Not applicable.

\section{Competing interest}

The authors declare no conflicts of interest.

\section{Author details}

${ }^{1}$ Engineering Research Centre of Cotton, Ministry of Education / College of Agriculture, Xinjiang Agricultural University, 311 Nongda East Road, 830052 Urumqi, China. ${ }^{2}$ State Key Laboratory of Crop Genetics and Germplasm Enhancement, Cotton Hybrid R \& D Engineering Center (the Ministry of Education), College of Agriculture, Nanjing Agricultural University, 210095 Nanjing, Jiangsu, China. ${ }^{3}$ College of Agriculture and Biotechnology, Zhejiang University, 210058 Hangzhou, Zhejiang, China. ${ }^{4}$ Hainan Institute of Zhejiang University, Yazhou Bay Science and Technology City, Building 11, Yonyou Industrial Park, Yazhou District, Hainan Province 572025 Sanya, China.
Received: 30 September 2020 Accepted: 4 June 2021

Published online: 13 June 2021

\section{References}

1. Ponting CP, Oliver PL, Reik W. Evolution and functions of long noncoding RNAs. Cell. 2009;136(4):629-41.

2. Ponjavic J, Ponting CP, Lunter G. Functionality or transcriptional noise? Evidence for selection within long noncoding RNAs. Genome Res. 2007; 17(5):556-65.

3. Glenfield C, McLysaght A. Pseudogenes Provide Evolutionary Evidence for the Competitive Endogenous RNA Hypothesis. Mol Biol Evol. 2018;35(12): 2886-99.

4. Zheng XM, Chen J, Pang HB, Liu S, Gao Q, Wang JR, Qiao WH, Wang H, Liu J, Olsen KM, et al. Genome-wide analyses reveal the role of noncoding variation in complex traits during rice domestication. Sci Adv. 2019;5(12): eaax3619.

5. Sarropoulos I, Marin R, Cardoso-Moreira M, Kaessmann H. Developmental dynamics of IncRNAs across mammalian organs and species. Nature. 2019; 571(7766):510-4

6. Ke L, Zhou Z, Xu XW, Wang X, Liu Y, Xu Y, Huang Y, Wang S, Deng X, Chen $\mathrm{LL}$, et al. Evolutionary dynamics of lincRNA transcription in nine citrus species. Plant J. 2019:98(5):912-27.

7. Hong YK, Ontiveros SD, Strauss WM. A revision of the human XIST gene organization and structural comparison with mouse Xist. Mamm Genome. 2000;11(3):220-4.

8. Karreth FA, Reschke M, Ruocco A, Ng C, Chapuy B, Leopold V, Sjoberg M, Keane TM, Verma A, Ala U, et al. The BRAF Pseudogene Functions as a Competitive Endogenous RNA and Induces Lymphoma In Vivo. Cell. 2015; 161(2):319-32.

9. Kapusta A, Kronenberg Z, Lynch VJ, Zhuo XY, Ramsay L, Bourque G, Yandell M, Feschotte C. Transposable Elements Are Major Contributors to the Origin, Diversification, and Regulation of Vertebrate Long Noncoding RNAs. Plos Genet. 2013;9(4):e1003470.

10. Song JH, Cao JS, Wang CG. BCMF11, a novel non-coding RNA gene from Brassica campestris, is required for pollen development and male fertility. Plant Cell Rep. 2013;32(1):21-30.

11. Zhang L, Wang M, Li N, Wang H, Qiu P, Pei L, Xu Z, Wang T, Gao E, Liu J, et al. Long noncoding RNAs involve in resistance to Verticillium dahliae, a fungal disease in cotton. Plant Biotechnol J. 2018;16(6):1172-85.

12. Zhang $Y C$, Chen $Y Q$. Long noncoding RNAs: new regulators in plant development. Biochem Biophys Res Commun. 2013:436(2):111-4.

13. Zhu QH, Wang MB. Molecular Functions of Long Non-Coding RNAs in Plants. Genes (Basel). 2012;3(1):176-90.

14. Rai MI, Alam M, Lightfoot DA, Gurha P, Afzal AJ. Classification and experimental identification of plant long non-coding RNAs. Genomics. 2019;111(5):997-1005.

15. Wierzbicki AT. The role of long non-coding RNA in transcriptional gene silencing. Curr Opin Plant Biol. 2012;15(5):517-22.

16. Joung J, Engreitz JM, Konermann S, Abudayyeh OO, Verdine VK, Aguet F, Gootenberg JS, Sanjana NE, Wright JB, Fulco CP, et al. Genome-scale activation screen identifies a IncRNA locus regulating a gene neighbourhood. Nature. 2017;548(7667):343-6

17. Kopp F, Mendell JT. Functional Classification and Experimental Dissection of Long Noncoding RNAs. Cell. 2018;172(3):393-407.

18. Yan $P$, Luo $S$, Lu JY, Shen X. Cis- and trans-acting IncRNAs in pluripotency and reprogramming. Curr Opin Genet Dev. 2017;46:170-8.

19. Heo JB, Sung S. Vernalization-mediated epigenetic silencing by a long intronic noncoding RNA. Science. 2011;331(6013):76-9.

20. Fedak H, Palusinska M, Krzyczmonik K, Brzezniak L, Yatusevich R, Pietras Z, Kaczanowski S, Swiezewski S. Control of seed dormancy in Arabidopsis by a cis-acting noncoding antisense transcript. Proc Natl Acad Sci U S A. 2016; 113(48):E7846-55

21. Hawkes EJ, Hennelly SP, Novikova IV, Irwin JA, Dean C, Sanbonmatsu KY COOLAIR Antisense RNAs Form Evolutionarily Conserved Elaborate Secondary Structures. Cell Rep. 2016;16(12):3087-96.

22. Swiezewski S, Liu F, Magusin A, Dean C. Cold-induced silencing by long antisense transcripts of an Arabidopsis Polycomb target. Nature. 2009; 462(7274):799-802.

23. Gai YP, Yuan SS, Zhao YN, Zhao HN, Zhang HL, Ji XL. A Novel LncRNA MuLnc1, Associated With Environmental Stress in Mulberry (Morus multicaulis). Front Plant Sci. 2018;9:669. 
24. Zhang X, Dong J, Deng F, Wang W, Cheng Y, Song L, Hu M, Shen J, Xu Q, Shen $F$. The long non-coding RNA IncRNA973 is involved in cotton response to salt stress. BMC Plant Biol. 2019;19(1):459.

25. Li R, Fu D, Zhu B, Luo Y, Zhu H. CRISPR/Cas9-mediated mutagenesis of IncRNA1459 alters tomato fruit ripening. Plant J. 2018;94(3):513-24.

26. Liu F, Xu Y, Chang K, Li S, Liu Z, Qi S, Jia J, Zhang M, Crawford NM, Wang Y. The long noncoding RNA T5120 regulates nitrate response and assimilation in Arabidopsis. New Phytol. 2019;224(1):117-31.

27. Huanca-Mamani W, Arias-Carrasco R, Cardenas-Ninasivincha S, Rojas-Herrera M, Sepulveda-Hermosilla G, Caris-Maldonado JC, Bastias E, MaracajaCoutinho V. Long Non-Coding RNAs Responsive to Salt and Boron Stress in the Hyper-Arid Lluteno Maize from Atacama Desert. Genes (Basel) 2018;9(3): 170.

28. Salih H, Gong W, He S, Xia W, Odongo MR, Du X. Long non-coding RNAs and their potential functions in Ligon-lintless-1 mutant cotton during fiber development. BMC Genom. 2019;20(1):661.

29. Cai P, Otten ABC, Cheng B, Ishii MA, Zhang W, Huang B, Qu K, Sun BK. A genome-wide long noncoding RNA CRISPRi screen identifies PRANCR as a novel regulator of epidermal homeostasis. Genome Res. 2020;30(1):22-34.

30. Qiu CW, Zhao J, Chen Q, Wu FB. Genome-wide characterization of drought stress responsive long non-coding RNAs in Tibetan wild barley. Environ Exp Bot. 2019;164:124-34.

31. Zhao T, Tao X, Feng S, Wang L, Hong H, Ma W, Shang G, Guo S, He Y, Zhou $B$, et al. LncRNAs in polyploid cotton interspecific hybrids are derived from transposon neofunctionalization. Genome Biol. 2018;19(1):195.

32. Wang M, Yuan D, Tu L, Gao W, He Y, Hu H, Wang P, Liu N, Lindsey K, Zhang $X$. Long noncoding RNAs and their proposed functions in fibre development of cotton (Gossypium spp.). New Phytol. 2015;207(4):1181-97.

33. Wendel JF. New World tetraploid cottons contain Old World cytoplasm. Proc Natl Acad Sci U S A. 1989;86(11):4132-6.

34. Hu Y, Chen J, Fang L, Zhang Z, Ma W, Niu Y, Ju L, Deng J, Zhao T, Lian J, et al. Gossypium barbadense and Gossypium hirsutum genomes provide insights into the origin and evolution of allotetraploid cotton. Nat Genet. 2019:51(4):739-48.

35. Paterson AH, Wendel JF, Gundlach H, Guo H, Jenkins J, Jin D, Llewellyn D, Showmaker KC, Shu S, Udall J, et al. Repeated polyploidization of Gossypium genomes and the evolution of spinnable cotton fibres. Nature. 2012;492(7429):423-7.

36. Zhang T, Hu Y, Jiang W, Fang L, Guan X, Chen J, Zhang J, Saski CA, Scheffler BE, Stelly DM, et al. Sequencing of allotetraploid cotton (Gossypium hirsutum L. acc. TM-1) provides a resource for fiber improvement. Nat Biotechnol. 2015;33(5):531-7.

37. Du X, Huang G, He S, Yang Z, Sun G, Ma X, Li N, Zhang X, Sun J, Liu M, et al. Resequencing of 243 diploid cotton accessions based on an updated A genome identifies the genetic basis of key agronomic traits. Nat Genet. 2018;50(6):796-802.

38. Wang M, Tu L, Yuan D, Zhu, Shen C, Li J, Liu F, Pei L, Wang P, Zhao G, et al. Reference genome sequences of two cultivated allotetraploid cottons, Gossypium hirsutum and Gossypium barbadense. Nat Genet. 2019;51(2): 224-9.

39. Ulitsky I. Evolution to the rescue: using comparative genomics to understand long non-coding RNAs. Nat Rev Genet. 2016;17(10):601-14.

40. Carninci P, Kasukawa T, Katayama S, Gough J, Frith MC, Maeda N, Oyama R, Ravasi T, Lenhard B, Wells C, et al. The transcriptional landscape of the mammalian genome. Science. 2005;309(5740):1559-63.

41. Zainab Q, Tanees CM, Du XM, Lori H, Tehseen AM. Review of oxidative stress and antioxidative defense mechanisms in Gossypium hirsutum updates L. in response to extreme abiotic conditions. J Cotton Res. 2021; 4(1):9.

42. Chekanova JA. Long non-coding RNAs and their functions in plants. Curr Opin Plant Biol. 2015;27:207-16.

43. Yuan J, Li J, Yang Y, Tan C, Zhu Y, Hu L, Qi Y, Lu ZJ. Stress-responsive regulation of long non-coding RNA polyadenylation in Oryza sativa. Plant J. 2018;93(5):814-27.

44. Pan YJ, Wang WS, Zhao XQ, Zhu LH, Fu BY, Li ZK. DNA methylation alterations of rice in response to cold stress. Plant Omics. 2011;4(7):364-9.

45. Sun $X$, Zheng $H$, Sui N. Regulation mechanism of long non-coding RNA in plant response to stress. Biochem Biophys Res Commun. 2018;503(2):402-7.

46. Li S, Yu X, Lei N, Cheng Z, Zhao P, He Y, Wang W, Peng M. Genome-wide identification and functional prediction of cold and/or drought-responsive IncRNAs in cassava. Sci Rep. 2017;7:45981.
47. Lu X, Wang X, Chen X, Shu N, Wang J, Wang D, Wang S, Fan W, Guo L, Guo $X$, et al. Single-base resolution methylomes of upland cotton (Gossypium hirsutum L.) reveal epigenome modifications in response to drought stress. BMC Genom. 2017;18(1):297.

48. Fernando VCD, Al Khateeb W, Belmonte MF, Schroeder DF. Role of Arabidopsis ABF1/3/4 during det1 germination in salt and osmotic stress conditions. Plant Mol Biol. 2018;97(1-2):149-63.

49. Medina-Puche L, Tan H, Dogra V, Wu M, Rosas-Diaz T, Wang L, Ding X, Zhang D, Fu X, Kim C, et al. A Defense Pathway Linking Plasma Membrane and Chloroplasts and Co-opted by Pathogens. Cell. 2020;182(5):1109-24.

50. Hezroni H, Koppstein D, Schwartz MG, Avrutin A, Bartel DP, Ulitsky I. Principles of long noncoding RNA evolution derived from direct comparison of transcriptomes in 17 species. Cell Rep. 2015;11(7):1110-22.

51. Schmid MW, Heichinger C, Coman Schmid D, Guthorl D, Gagliardini V, Bruggmann R, Aluri S, Aquino C, Schmid B, Turnbull LA, et al. Contribution of epigenetic variation to adaptation in Arabidopsis. Nat Commun. 2018;9(1):4446.

52. Kazachenka A, Bertozzi TM, Sjoberg-Herrera MK, Walker N, Gardner J, Gunning R, Pahita E, Adams S, Adams D, Ferguson-Smith AC. Identification, Characterization, and Heritability of Murine Metastable Epialleles: Implications for Non-genetic Inheritance. Cell. 2018;175(5):1259-71.

53. Shen YT, Zhang JX, Liu YC, Liu SL, Liu Z, Duan ZB, Wang Z, Zhu BG, Guo YL, Tian ZX. DNA methylation footprints during soybean domestication and improvement. Genome Biol. 2018;19(1):1-14.

54. Kooke R, Johannes F, Wardenaar R, Becker F, Etcheverry M, Colot V, Vreugdenhil $\mathrm{D}$, Keurentjes JJ. Epigenetic basis of morphological variation and phenotypic plasticity in Arabidopsis thaliana. Plant Cell. 2015;27(2):337-48.

55. He L, Wu W, Zinta G, Yang L, Wang D, Liu R, Zhang H, Zheng Z, Huang $H$, Zhang $Q$, et al. A naturally occurring epiallele associates with leaf senescence and local climate adaptation in Arabidopsis accessions. Nat Commun. 2018:9(1):460.

56. Jiang C, Mithani A, Belfield EJ, Mott R, Hurst LD, Harberd NP. Environmentally responsive genome-wide accumulation of de novo Arabidopsis thaliana mutations and epimutations. Genome Res. 2014;24(11):1821-9.

57. Iyer MK, Niknafs YS, Malik R, Singhal U, Sahu A, Hosono Y, Barrette TR, Prensner JR, Evans JR, Zhao S, et al. The landscape of long noncoding RNAs in the human transcriptome. Nat Genet. 2015;47(3):199-208.

58. Necsulea A, Soumillon M, Warnefors M, Liechti A, Daish T, Zeller U, Baker JC, Grutzner F, Kaessmann H. The evolution of IncRNA repertoires and expression patterns in tetrapods. Nature. 2014;505(7485):635-40.

59. Ruan X, Li P, Chen Y, Shi Y, Pirooznia M, Seifuddin F, Suemizu H, Ohnishi Y, Yoneda N, Nishiwaki M, et al. In vivo functional analysis of non-conserved human IncRNAs associated with cardiometabolic traits. Nat Commun. 2020;11(1):45.

60. Liu SJ, Horlbeck MA, Cho SW, Birk HS, Malatesta M, He D, Attenello FJ, Villalta JE, Cho MY, Chen Y, et al. CRISPRi-based genome-scale identification of functional long noncoding RNA loci in human cells. Science. 2017; 355(6320):aah7111.

61. Furci L, Jain R, Stassen J, Berkowitz O, Whelan J, Roquis D, Baillet V, Colot V, Johannes F, Ton J. Identification and characterisation of hypomethylated DNA loci controlling quantitative resistance in Arabidopsis. Elife. 2019;8:e40655.

62. Yang J, Meng X, Pan J, Jiang N, Zhou C, Wu Z, Gong Z. CRISPR/Cas9-mediated noncoding RNA editing in human cancers. RNA Biol. 2018;15(1):35-43.

63. Kohel RJ. Genetic Nomenclature in Cotton. J Hered. 1973;64(5):291-5.

64. Gao X, Britt RC Jr, Shan L, He P. Agrobacterium-mediated virus-induced gene silencing assay in cotton. J Vis Exp. 2011(54):e2938.

65. Ma D, Hu Y, Yang C, Liu B, Fang L, Wan Q, Liang W, Mei G, Wang L, Wang $\mathrm{H}$, et al. Genetic basis for glandular trichome formation in cotton. Nat Commun. 2016;7:10456.

66. Wang $Y$, Tang H, Debarry JD, Tan X, Li J, Wang X, Lee TH, Jin H, Marler B, Guo H, et al. MCScanX: a toolkit for detection and evolutionary analysis of gene synteny and collinearity. Nucleic Acids Res. 2012;40(7):e49.

67. Pertea M, Pertea GM, Antonescu CM, Chang TC, Mendell JT, Salzberg SL. StringTie enables improved reconstruction of a transcriptome from RNA-seq reads. Nature biotechnology. 2015;33(3):290-5.

68. Brown J, Pirrung M, McCue LA. FQC Dashboard: integrates FastQC results into a web-based, interactive, and extensible FASTQ quality control tool. Bioinformatics. 2017;33(19):3137-9.

69. Kim D, Langmead B, Salzberg SL. HISAT: a fast spliced aligner with low memory requirements. Nat Methods. 2015;12(4):357-60.

70. Li H, Handsaker B, Wysoker A, Fennell T, Ruan J, Homer N, Marth G, Abecasis G, Durbin R, Genome Project Data Processing S. The Sequence Alignment/ Map format and SAMtools. Bioinformatics. 2009;25(16):2078-9. 
71. Love Ml, Huber W, Anders S. Moderated estimation of fold change and dispersion for RNA-seq data with DESeq2. Genome Biol. 2014;15(12):550.

72. You Q, Xu W, Zhang K, Zhang L, Yi X, Yao D, Wang C, Zhang X, Zhao X, Provart NJ, et al. ccNET: Database of co-expression networks with functional modules for diploid and polyploid Gossypium. Nucleic Acids Res. 2017; 45(D1):D1090-9.

\section{Publisher's Note}

Springer Nature remains neutral with regard to jurisdictional claims in published maps and institutional affiliations.

Ready to submit your research? Choose BMC and benefit from:

- fast, convenient online submission

- thorough peer review by experienced researchers in your field

- rapid publication on acceptance

- support for research data, including large and complex data types

- gold Open Access which fosters wider collaboration and increased citations

- maximum visibility for your research: over $100 \mathrm{M}$ website views per year

At BMC, research is always in progress.

Learn more biomedcentral.com/submissions 